\title{
Electrochemical Behaviour of Tin in a LiCl-KCl Eutectic Melt
}

\author{
Yanqing $\mathrm{Cai}^{1,{ }^{*}, \text { Xinggang Chen }}{ }^{1}$, Qian $X u^{2}$, Ying $X u^{1}$ \\ ${ }^{1}$ Hebei Provincial Key Laboratory of Inorganic Nonmetallic Materials, College of Material Science \\ and Engineering, North China University of Science and Technology, Tangshan, China \\ ${ }^{2}$ School of Materials Science and Engineering, Shanghai University, Shanghai, 200072, PR China \\ *E-mail: caiyanqing126@126.com
}

doi: $10.20964 / 2018.11 .21$

Received: 30 June 2018 / Accepted: 30 August 2018 / Published: 1 October 2018

The electrochemical behaviour and thermodynamic properties of $\mathrm{SnCl}_{2}$ in a $\mathrm{LiCl}-\mathrm{KCl}$ eutectic melt was investigated on graphite and Mo electrodes at $500^{\circ} \mathrm{C}$ by cyclic voltammetry, chronopotentiometry, square wave voltammetry, and open circuit chronopotentiometry. Two redox couples of tin ions due to $\mathrm{Sn}(\mathrm{IV}) / \mathrm{Sn}(\mathrm{II})$ and $\mathrm{Sn}(\mathrm{II}) / \mathrm{Sn}$ were obtained, and the cathodic peak potentials were found to be $0.50 \mathrm{~V}$ and $-0.50 \mathrm{~V}$, respectively. The reduction reactions of $\mathrm{Sn}(\mathrm{IV}) / \mathrm{Sn}(\mathrm{II})$ and $\mathrm{Sn}(\mathrm{II}) / \mathrm{Sn}$ are quasi-reversible processes and occur with two exchanged electrons, respectively. The diffusion coefficients of the $\mathrm{Sn}(\mathrm{IV})$ and $\mathrm{Sn}(\mathrm{II})$ ions were also determined on graphite electrode by the Berzins-Delahay equation, which were $2.68 \times 10^{-5} \mathrm{~cm}^{2} / \mathrm{s}$ and $5.19 \times 10^{-5} \mathrm{~cm}^{2} / \mathrm{s}$, respectively. In addition, square wave voltammetry and open circuit chronopotentiometry experiments performed on a Mo electrode further indicated that the reduction of Sn(II) into Sn metal occurred in a single step and two electrons were exchanged. The research lays a foundation for electrolytic refining and electrodeposition of $\mathrm{Zr}-\mathrm{Sn}$ alloy.

Keywords: molten chlorides, tin, diffusion coefficient, electrochemical behaviour

\section{FULL TEXT}

(C) 2018 The Authors. Published by ESG (www.electrochemsci.org). This article is an open access article distributed under the terms and conditions of the Creative Commons Attribution license (http://creativecommons.org/licenses/by/4.0/). 